\title{
Sobrevivências da "faca de ponta": Um estudo sobre a constituição do sertanejo a partir do objeto e da ressignificação do objeto a partir do design
}

Survival of the "faca de ponta": A study on the constitution of the sertanejo from the object and the resignification of the object from the design

ARAUJO, Manoel Deisson Xenofonte; Mestre; Universidade Federal do Cariri - UFCA

deisson.araujo@ufca.edu.br

DANTAS, Ney Brito; Doutor; Universidade Federal de Pernambuco - UFPE

ney.dantas@gmail.com

VIDELA, Ana Neuza Botelho; Doutora; Universidade Federal do Cariri - UFCA

ana.videla@ufca.edu.br

\section{Resumo}

O artigo pretende demonstrar a importância da "faca de ponta" enquanto item representante da cultura material nordestina, apresentando relatos e excertos literários que evidenciam este artefato como constituinte da figura do sertanejo tradicional. Ressaltamos também a capacidade de ressonância que este objeto emite, constituindo-se dessa maneira como um valioso referencial para criação em design, ação esta que lhe garantiria uma nova sobrevivência.

Palavras Chave: Cultura material; Design; Faca de ponta; Sertanejo

\begin{abstract}
This article intends to demonstrate the importance of the "faca de ponta" as a representative item of the material culture of the Northeast, presenting reports and literary passages that show this artifact as a constituent of the traditional sertanejo figure. We also emphasize the resonance that this object emits, constituting in this way a valuable reference for creation in design, action that can guarantee you a new survival
\end{abstract}

Keywords: Material culture; Design; Faca de ponta; Sertanejo

\section{Introdução}

O presente artigo trata-se de um desdobramento de minha dissertação de mestrado, a qual versa sobre os campos da antropologia e do design. As teorias antropológicas nos foram úteis para compreender as relações constituintes entre determinado artefato e seu contexto cultural, enquanto que o design nos é percebido enquanto atividade mediadora desta relação a partir das possibilidades de ressignificação dos artefatos, inserindo-os em novos contextos e sentidos. 
Concordamos dessa maneira com Irene Rodrigues (2009):

\begin{abstract}
Desta forma o design abre novos caminhos na densidade cultural apontando rumos futuros, desencadeando relações, modelando pensamentos, dialogando com a sociedade, construindo valores, símbolos, e novos significados. Isto é interferência e, por isso mesmo, requer do designer responsabilidade social. Ser designer "é gerar soluções a partir de variáveis concretas." (RODRIGUES, 2009, p. 95)
\end{abstract}

Seguindo este raciocínio, analisaremos aqui um artefato peculiar de determinado tempo e espaço sociocultural, enfatizando o poder de "ressonância" e sua consequente capacidade de ressignificação pelas mãos do designer. Tal artefato trata-se da "faca de ponta", um objeto de fabricação artesanal e de uso comum no nordeste brasileiro das primeiras décadas do século XX, tendo seu auge de produção entre os anos 10 até os anos 50 aproximadamente, quando passam pouco a pouco a serem substituídas pelas facas industriais.

Figura 01 - Exemplares de faca Caroca datada de1930 a 1950

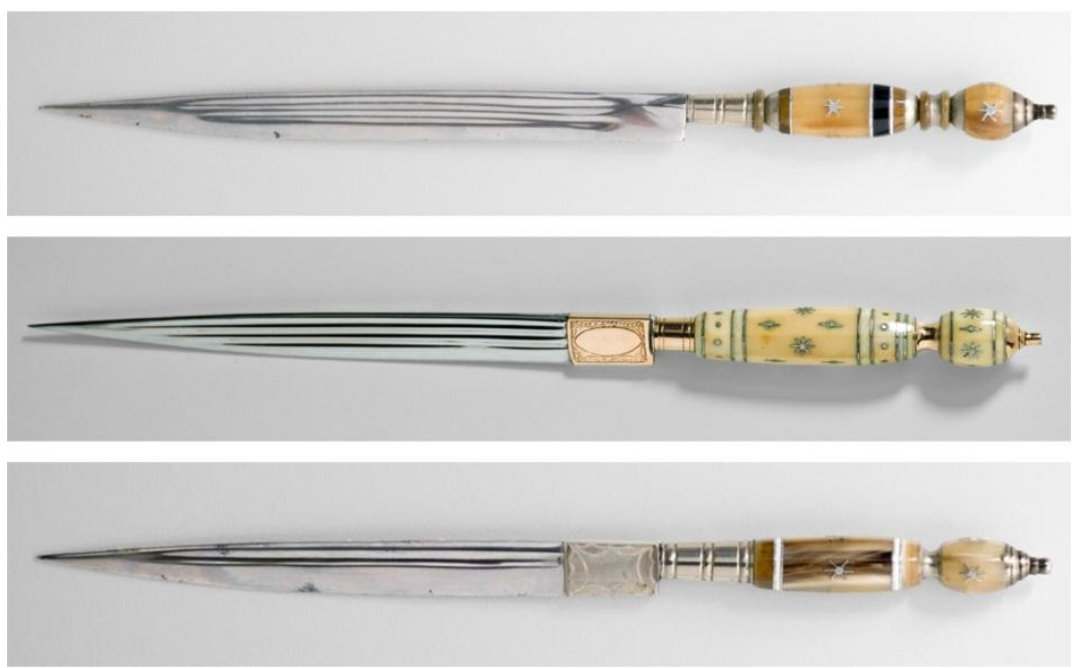

Fonte: : <www.colecaoorsini.com.br/ > Acesso em: 01 Fev. 2013

Mais do que um simples instrumento de utilização prática e cotidiana, acreditamos que a "faca de ponta" constituía a figura do sertanejo tradicional, carregando os indispensáveis signos representativos de honra, hombridade e valentia comuns a esta persona. Para comprovarmos esta hipótese, evocaremos discursos oriundos da oratória e poesia populares no intuito de demonstrar a importância deste artefato na construção cultural deste ser.

Ilustramos ainda ao longo do trabalho alguns exemplares destas facas, a fim de demonstrar o requinte de produção, materiais e acabamento despendidos na sua execução, algo que evidencia também o valor deste objeto em seu contexto sertanejo. Por fim, lançaremos um olhar sobre a possibilidade de uma nova sobrevivência deste artefato a partir da ação do designer.

\title{
2 Objetos constituem as pessoas
}

Nos estudos antropológicos contemporâneos têm-se observado uma nova tendência de abordagem dos objetos constituintes da cultura material de determinada sociedade ou grupo social. Esta abordagem distingue-se da até então comum aplicação das teorias semióticas sobre o objeto, retirando-o da aparente inércia e começando a tratá-lo como fato social, ou seja, como algo dotado de poder de ação sobre o mundo. (D. LEITÃO; R. MACHADO, 2010). 
Dentre os autores que atuam sobre este viés de pensamento, destaca-se Daniel Miller, antropólogo que enfatiza a maneira da qual os objetos "fazem" as pessoas: "a cultura material implica que grande parte do que nos torna o que somos existe não por meio da nossa consciência ou do nosso corpo, mas como um ambiente exterior que nos habitua e incita" (MILLER, 2013 p.79).

A validação de sua hipótese é perfeitamente ilustrada a partir da aplicação da teoria sobre aspectos relacionados à indumentária de determinado universo cultural. $\mathrm{O}$ autor revela por exemplo, o quanto que em Trinidad as pessoas usam roupas "para descobrir quem são naquele momento particular do tempo", enquanto que na Índia a indumentária reflete a expectativa cultural da experiência de ser mulher, e já em Madri ela ajuda a "preservar o ideal cosmológico da cidade como centro da civilização" (MILLER, 2013 p.63).

A partir deste conceito, acreditamos que a "faca de ponta" era indispensável na constituição do sertanejo tradicional, entendido aqui a como uma imagem construída culturalmente a qual preservava uma aura de virilidade, hombridade e honra. Os processos históricos, sociais e culturais que "inventaram" este ser foram amplamente explorados por Durval Albuquerque, cabendo a nós aqui somente ilustrar o papel da faca neste processo. Apresentaremos a seguir nosso objeto de estudo.

\section{As "facas de ponta" nordestinas como constituintes do sertanejo}

Item indispensável ao sertanejo, a "faca de ponta" foi a tipologia mais proliferada no nordeste, desempenhando as mais variadas funções práticas exigidas nas tarefas agrícolas, pecuárias ou domésticas. Desde extrair um dente, este objeto servia-lhe ainda para "picar o fumo de corda e emparelhar a palha de milho do cigarro, como cortar uma vergôntea de pau, sangrar uma rês, tirar um couro, descarnar, retirar um estrepe ou espinho" (LAMARTINE, 1988, p. 32)

Figura 02 - Faca que pertenceu a Maria Bonita

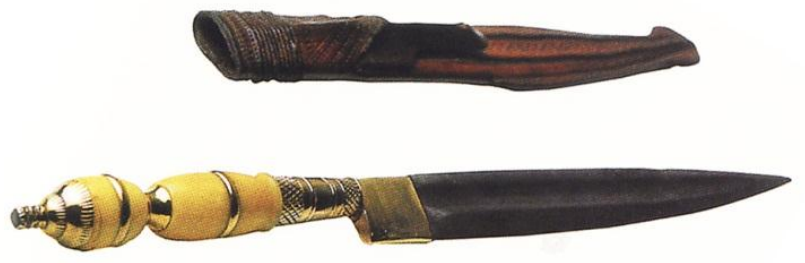

Fonte: DE MELLO (2012)

Cabe salientar que o formato e tamanho de lâmina - 30 a $40 \mathrm{~cm}$ em média - da "faca de ponta", contribuiu para a versatilização deste artefato em detrimento a outros itens mais específicos, tais quais a "faca de arrasto" que tinha longa lâmina propícia ao desmatamento, ou o punhal, que se configurava mais como uma arma por não conter geralmente gume, mas somente "ponta". 


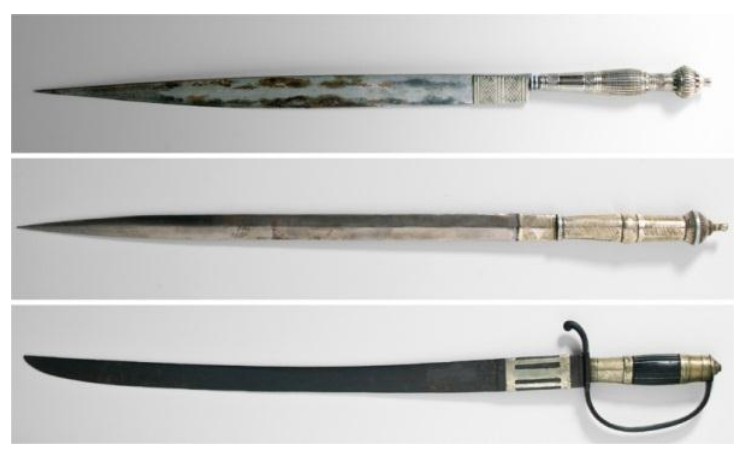

Fonte: <www.colecaoorsini.com.br/ > Acesso em: 01 Fev. 2013

Para além do auxílio às necessidades diárias, acreditamos que a faca "constituía" a figura do sertanejo tradicional, operando também em níveis simbólicos de auto-representação. Como já mencionamos, tal afirmação é amparada pelas proposições de Miller (2013) a cerca do universo da cultura material, sob o qual lança a atenção de que as coisas fazem as pessoas tanto quanto as pessoas fazem as coisas. De início, podemos visualizar mais facilmente a proposição acima tendo como exemplo os punhais dos cangaceiros, os quais tinha lugar de destaque na composição de sua indumentária; "à vista de todos, desfrutável ao primeiro olhar ou a primeira fotografia" (PERNAMBUCANO DE MELLO, 2010, p.126).

Figura 04 - Alguns cangaceiros famosos da década de 10 e 20
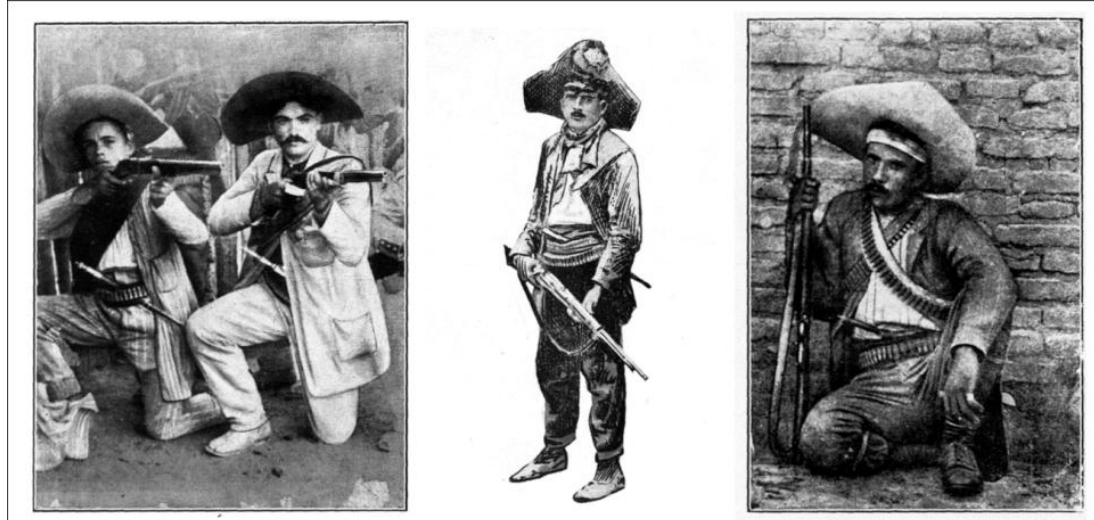

Fonte: DE OLIVEIRA (1920)

Os cabos das facas dos cangaceiros eram ricamente adornados, por vezes com anéis de ouro que eram cedidos pelo próprio cangaceiro no ato da encomenda. As dimensões exageradas das lâminas cumpriam ainda a função simbólica de lhes conferir imponência e autoridade. Lampião por exemplo portava um punhal de $67 \mathrm{~cm}$ de comprimento, interpretado inclusive por seus comparsas como um exagero de vaidade (DE MELLO, 2012). Mesmo conceito se aplicava ao porte de sabres por fazendeiros, coronéis ou figuras políticas do sertão, de onde teria se originado a expressão denotativa de autoridade "Homem do facão grande" (LAMARTINE, 1988). 


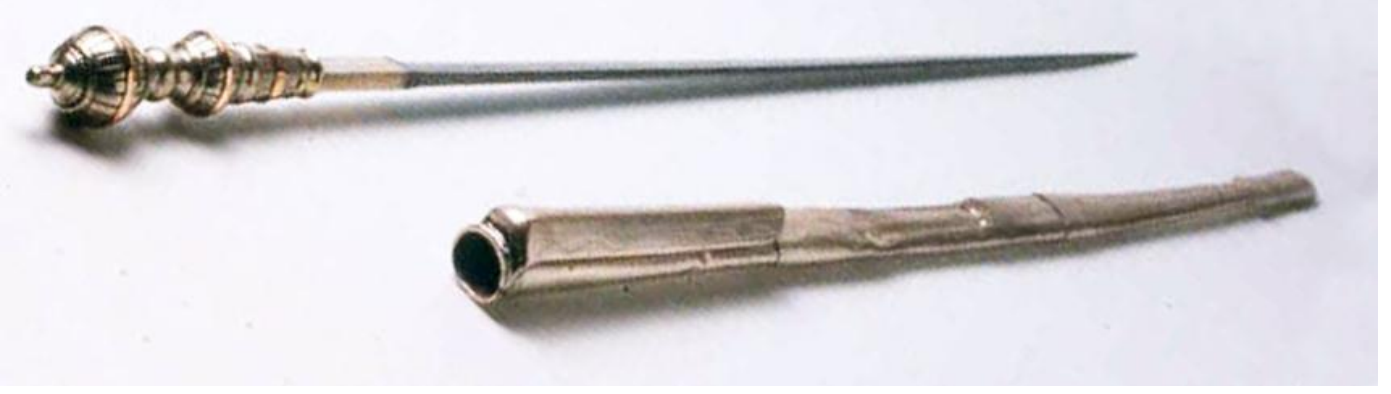

Fonte: Pernambucano de Mello (2010)

Haviam ainda expressões simbólicas relacionadas à honra do uso da faca enquanto arma, como descreve Lamartine:

E naqueles ermos e começos muitos espiavam com desconfiança e desprezo para quem conduzia uma arma de fogo. Era a arma preferida do tocaieiro, traiçoeira e capaz de fazer o mal sem carecer de tomar chegada. Daí apreciarem e respeitarem o ferro-frio. É que ele tem a lealdade do corpo-a-corpo, o olho no olho e o alcance de um braço. (LAMARTINE, 1988, p.09).

Tal "lealdade" a nosso ver, faz parte do mesmo imaginário sertanejo que, segundo Luitgarde de Oliveira, "deu formato de epopeia às narrativas dos confrontos entre valentes, mitologizados como símbolos de coragem do homem sertanejo" (BARROS, 1998, p.160). Nosso comentário é elucidado no seguinte excerto:

Em suas fainas cotidianas, nas lutas de vida e morte por questões econômicas ou de honra, o homem sertanejo constrói-se num imaginário em que transforma as histórias locais, regionais, nacionais e seus próprios feitos, em grandes gestas sertanejas". Nelas se evidencia uma consciência de que as lutas se desenvolvem não só em função da posse, defesa ou conquista de bens materiais. Valores como o cumprimento das leis, a proteção à honra da família - representada pela coragem e o bom comportamento dos homens, associados à pureza sexual das donzelas e recato de viúvas e mulheres casadas - , a obediência à Igreja Católica, o respeito aos mais velhos e padrinhos; a caridade; a sobriedade e modéstia no vestir e no falar, o "respeito ao alheio", articulam-se no código de "honra sertaneja". (BARROS, 1998, p. 162)

Manifestações dos "códigos de honra sertaneja" são ilustradas nas diversas narrativas populares, as quais enalteciam o duelo mano-a-mano que a "faca de ponta" proporcionava, saindo assim expressões como "amarrar os panos": denotação de uma modalidade de luta na qual os oponentes amarravam as mangas de suas camisas para duelarem com faca até a morte. Leonardo Mota (2002) descreve umas destas estórias populares, tendo como protagonistas os afamados facínoras Antonio Godê e Zé Pinheiro da cidade de Juazeiro do Norte-CE. Na narrativa, Antonio Godê desafia Zé Pinheiro ao saber que este havia bravateado ser mais "homem" do que o primeiro:

- Zé Pinheiro, meu caboco, deixa eu ver aí a fralda de tua camisa!

- Que negócio é este, Antonio Godê?

- Nada. É uma brincadeira, é uma caçoada que eu quero te ensinar...

- Agora que nós estamo amarrado um no outro e nenhum de nós pode correr, bata a mão 
à sua faca, cabra severgonho, que chegou a hora de se decidir quem de nós dois é o home mais home! (MOTA, 2002, p. 33-34)

Este episódio se encerra sem derramamento de sangue graças à solicitação de desculpas de Zé Pinheiro a Antonio Godê, o qual se contentou em levar como troféu um pedaço da manga da camisa do oponente (MOTA, 2002). O mesmo não ocorre entretanto na narrativa tida por cantadores, memorialistas e informantes como a maior gesta sertaneja, protagonizada por Sinhô Pereira e Antonio de Umburana: Representantes de clãs familiares rivais, os dois findam após longo combate de fogo a "amarrarem os panos" e duelarem com punhais até a morte, donde prevalece o primeiro e falece o segundo. Ambos, no entanto, virariam sinônimo de heróis e protótipos da cultura sertaneja (BARROS, 1998).

Seguindo o mesmo discurso de honra, havia ainda relatos de sertanejos que recusavam a utilizar de armas de fogo nos conflitos armados, encarando o inimigo face-a-face com o punhal em mãos, tal como ilustra o depoimento de um jagunço participante à época do evento bélico que ficou conhecido como a "Sedição de Juazeiro" em Juazeiro do Norte -CE: "Aqui tem gente de toda parage. Da Parahyba tem, da pruvinça de Alagoas e tem o cabrual do Riacho do Navio, de Pernambuco, que é o mais danisco que eu já tive de aperciá. Gente que só usa tomá trincheira a punhal, gente ispromentada..." (A PÁTRIA, Ed. 192, 20 maio 2014).

Visto como uma extensão de sua hombridade, a faca era indispensável e de uso exclusivo a cada sertanejo, sem a qual - parafraseando Gustavo Barroso - estaria "moralmente morto" assim como o sertanejo que não se vinga (MELLO, 2004). Podemos ilustrar tal percepção a partir do caso narrado por Peixoto Júnior (1996) no qual o então civil João Marcelino - que se tornaria o afamado João 22 - decide entrar para a vida do cangaço após ter sua faca "desonrada" e decidir "vingá-la", vociferando as palavras: "De hoje em diante a minha faca tá desmoralizada! Se eu não vingá ela, Santa Luzia me estrale os óios. Essa faca vai parir muita faquinha!" (PEIXOTO, 1996, p.12)

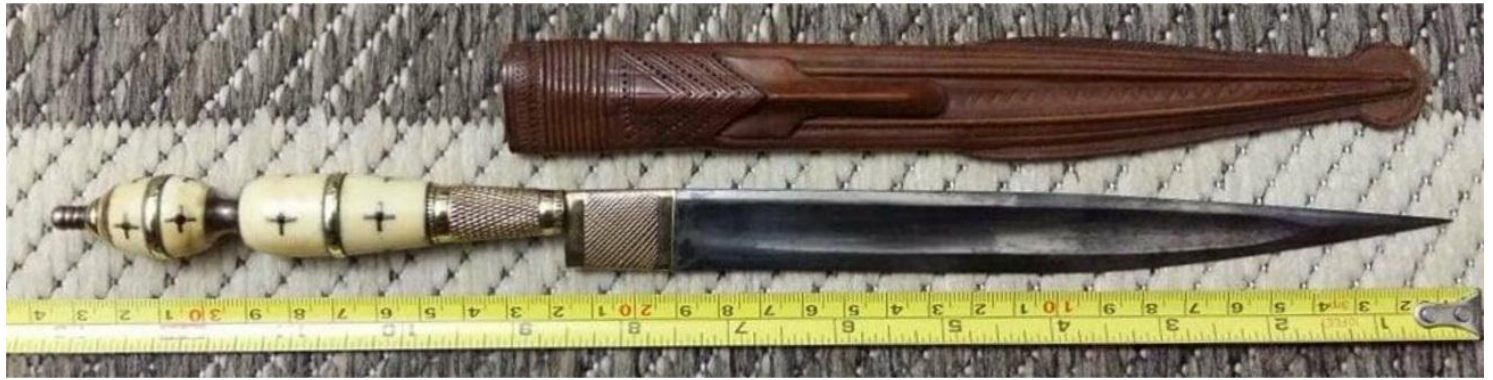

Fonte: Coleção particular

O cancioneiro popular também tratou de desenhar a figura do nordestino enquanto homem de honra inabalável. Neste sentido, Luitgarde observa a influência exercida por impressos do final do séc. XIX, tais quais os livros Carlos Magno e os doze pares de França; A história da donzela Theodora e As canções de Rolando, obras que segundo a autora constituíam verdadeiros "guias de procedimentos sociais" e contribuíram para o nascimento de versos populares com 
discursos similares ao reproduzido abaixo:

Honra é jóia, que mais val,

A tudo o mais preferida:

Pela honra se arrisca a vida,

Que a honra é vida imortal.

Mentir na realidade, leva dos vícios ao cabo:

Pois da mentira é o diabo,

E deus é a suma verdade

(BARROS, 1998, p.162)

Se a construção do imaginário popular sobre a figura do sertanejo enquanto homem corajoso, honrado e valente se deve em parte à literatura popular em suas raízes europeias, a cristalização desse conceito se deve também aos discursos literários de uma elite intelectual tradicionalista que traduz os códigos populares para uma categoria erudita:

O cordel representava a resistência dessa cultura que era a expressão do homem nordestino, que lhe dava perfil, que o delimitava e definia. Por isso, uma das principais atividades a que se dedicarão os regionalistas e tradicionalistas é a de tentar "preservar a cultura popular nordestina", já que a cultura das elites há muito vinha sendo corrompida. (ALBUQUERQUE JÚNIOR, 2003 p. 198 - 199)

Dentre os tradicionalistas citados por Albuquerque Júnior (Op. cit), encontram-se além do supracitado Leonardo Mota, os memorialistas Gilberto Freire, Câmara Cascudo e Eloy de Souza, figuras responsáveis pela construção de uma imagem sobre a cultura popular nordestina que se supria dos comportamentos, atitudes, hábitos e manifestações artísticas da tradição rural, aspectos dos quais, aos olhos destes autores, estariam desaparecendo. Para eles, a valorização dessa cultura rústica tinha fundamentos no caráter histórico dos conflitos e lutas do homem do nordeste, os quais seriam o principal elemento constituidor de sua virilidade.

Dessa maneira, os discursos relacionados à honra, coragem ou valentia do nordestino em associação ao porte da faca que eram comuns à literatura de cordel são agora enaltecidos e revisitados em prosa e poesia por estes autores. Podemos citar, por exemplo, o já característico romantismo medievalesco de Ariano Suassuna no livro Romance da Pedra do Reino e o Príncipe do Sangue do Vai-e-Volta, no qual cita inclusive o livro Carlos Magno e os doze pares de França:

Cheguei mesmo a ir além do meu mestre, Clemente: porque, lendo na História de Carlos Magno e os Doze Pares de França, que era costume os grandes Cavaleiros antigos colocarem nomes de batismo em suas armas, meu facão foi batizado como "a legendária espada Pajeú e meu ferrão como "a famosa lança Cariri", ambos muitos superiores à "Durindana", do Conde Roldão (SUASSUNA, 2012, p. 257).

Seguindo o mesmo romantismo, Lamartine (1988) também associa o sertanejo e sua "faca de ponta" ao cavaleiro e sua espada:

E o ferro de corte talvez tenha entranhado no inconsciente coletivo como símbolo de poder - herança histórica do homem sertanejo. Na mente deles quem sabe, tenha principiado pelas citações bíblicas onde até a espada do espírito é usada para significar a palavra de Deus. Também nas estórias de Trancoso e romances de folhetos que falam nos juramentos pela cruz da espada, na degradação pela espada (ou espora) quebrada, na rendição pela entrega da espada e em toda a sua simbologia de poder e glória. Era, assim, a arma nobre, dos poucos sobejos da romântica cavalaria, arma de ataque ou defesa no peito a peito, olho a olho, no corpo a corpo. (LAMARTINE, 1988, p. 16) 
Não menos poético que Lamartine ou Suassuna, Gerardo Melo Mourão (1966), evoca por sua vez a imagem de Aquiles:

\begin{abstract}
Era apenas uma insignificante faca de ponta, dessa a que chamamos no sertão de "Parnaíba ou de "Pajeú"... Era apenas uma insignificante faca do nordeste brasileiro. Mas de repente, o clarão de eu aço polido, ao clarão dos homens curiosos e das mulheres elegantes, eu me lembrei de Aquiles na corte de Licomedes. E não sei se a presença de Aquiles, não sei se a presença da arma típica dos homens da minha terra, não sei se os belos olhos negros, verdes, azuis, castanhos das senhoras chilenas que faiscavam ao fascínio da folha do punhal, ergueram diante de todos nós, no meio daquela sala e daquela noite de inverno, como um golpe de beleza e de dor inumerável, a imagem viva da unidade da América. (MOURÃO, 1966, p.13-14).
\end{abstract}

Acreditamos dessa maneira, que tais enaltecimentos literários sobre a honra nordestina associada ao uso da faca contribuíram também no processo de "souvenirização" deste item, ao que passa em determinado momento a ser comercializado como artigo de lembrança nas feiras regionais. De fato a própria imagem do sertanejo tradicional passa aos poucos a figurar como lembrança, e as facas que eram próprias dos vaqueiros, agricultores ou cangaceiros hoje habitam as prateleiras de acervos museológicos e particulares.

\title{
4 Considerações finais
}

Apesar de ter sua produção praticamente extinta no nordeste, acreditamos que as tradicionais "facas de ponta" são passíveis de uma nova sobrevivência pela atuação do designer. Poderíamos aqui citar inúmeros aspectos sintáticos que evidenciam o requinte de execução dos artesãos cuteleiros, os quais, além de sua própria interpretação artística, imprimiam na peça belíssimos traços hibridizados de culturas europeias, mouriscas e africanas. Optamos, no entanto por centrar nossa justificativa em aspectos mais semânticos.

Partimos dessa maneira do conceito de "ressonância" dos artefatos, citado por Gonçalves (2007) como um dos elementos indispensáveis para a promoção de determinado objeto à categoria de patrimônio cultural. Este conceito é na verdade uma adaptação textual de Stephen Greenblatt, ao que afirma que seria o "poder de um objeto exposto atingir um universo mais amplo, para além de suas fronteiras formais, o poder de evocar no expectador as forças culturais complexas e dinâmicas das quais ele emergiu e das quais ele é, para o expectador, o representante" (GONÇALVES, 2007, p. 215). O autor enaltece então a ressonância de um artefato como a possibilidade deste de sair da inerte exposição museológica de representação do passado, e passar também a servir como forma de comunicação criativa entre passado e presente, cosmo e sociedade, cultura e indivíduos e história e memória. Em outras palavras o artefato deve também possibilitar a geração de novas ideias, experiências, ressignificações, e atitudes junto ao espectador.

A nosso ver reside aí a maior oportunidade de uma nova sobrevivência deste artefato. Como demonstramos, a "faca de ponta" era um dos objetos constituintes do sertanejo tradicional, sem a qual estaria desprovido de sua honra, ou seja, estaria "moralmente morto". Longe de querer ressuscitar dos tempos remotos esta persona cultural ou este objeto, acreditamos na capacidade de se gerarem novas sobrevivências e significados a partir da utilização deste material como referência criativa na configuração de outros produtos. 
Podemos citar, por exemplo, o sucesso do trabalho do mestre Espedito Seleiro, artesão do couro residente da cidade de Nova Olinda CE. Vendo a diminuição de demanda de artefatos para vaqueiros, Espedito redirecionou sua produção para um novo público a partir dos anos 90, confeccionando mochilas, bolsas e sapatos para todos os gêneros, além de mobiliário e artigos de decoração diversos.

Voltando os olhos para a "faca de ponta", é interessante notar a relação histórica entre a cutelaria tradicional e a ourivesaria, a qual já justificaria o desenvolvimento de peças ou coleções desenvolvidas sobre este tema. Somem-se ainda as capacidades de ressignificação deste artefato na configuração de peças gráficas, produtos de moda ou mobiliário. Enfim, esperamos dessa maneira que o presente trabalho contribua para uma nova e duradoura sobrevivência das "facas de ponta".

\section{REFERÊNCIAS}

ALBUQUERQUE JÚNIOR, Durval Muniz . Nordestino: Uma invenção do falo; uma História do gênero masculino (Nordeste - 1920/1940). Maceió: Editora Catavento, 2003.

BARROS, Luitgarde Oliveira Cavalcanti. Antropologia da honra: uma análise das guerras sertanejas, in: revista de ciência sociais V.29 N. 1/2 1998

BATISTA, Francisco das Chagas. Literatura popular em verso: antologia. Brasília: MEC; Rio de Janeiro: Fundação Casa de Rui Barbosa, 1977. 280 p.

DE MELLO, Frederico Pernambucano. Estrelas de Couro: A estética do cangaço. 2a Ed. São Paulo. Escrituras, 2012. 253p.

DE OLIVEIRA, Xavier. Beatos e cangaceiros. História real, observação pessoal e impressões psicológicas de alguns dos mais celebres cangaceiros do Nordeste. Rio de Janeiro: [s.n.], 1920.

GONÇALVES, José Reginaldo Santos. Antropologia dos objetos: coleções, museus e patrimônios. Rio de Janeiro: IPHAN, 2007.

JÚNIOR, José Peixoto. Bom Deveras e Seus Irmãos 2a Ed. Goiania: Kelps, 2009.

LAMARTINE, Oswaldo. Apontamentos Sobre a Faca de Ponta. Rio de Janeiro. Fundação Ozelita Cascudo Rodrigues, 1988. 66p.

LEITÃO, D. K.; MACHADO, R. Tratar as coisas como fatos sociais: metamorfoses nos estudos sobre cultura material. Revista Mediações, Londrina, v. 15, n. 2, p. 231-247, jul/dez. 2010

MILLER, Daniel. Trecos, Troços e coisas: Estudos antropológicos sobre a cultura material Tradução: Renato Aguiar. Rio de Janeiro: Zahar, 2013

MOTA, Leonardo; No tempo de Lampião; Prefácio de Fran Martins. 3ạ ed. Rio-São PauloFortaleza: ABC Editora, 2002 
MOURÃO, Gerardo Melo. Frei e Chile num continente ocupado. Rio de Janeiro: Tempo Brasileiro, 1966

OLIVEIRA, Xavier de. Beatos e cangaceiros. Rio de Janeiro: [s.n.], 1920]

RODRIGUES, Irene G. O olhar antropológico do designer. In: Faces do design 2: ensaios sobre arte, cultura visual, design gráfico e as novas mídias. São Paulo: Edições Rosari, 2009. p. 8197.

SILVA, Caetano Cosme da. Assassino da honra ou a louca do jardim. Recife: Editor Propriétário. João José da Silva: São Paulo E. Luzeiro do Norte 19--)

SUASSUNA, Ariano. Romance 'a pedra do Reino e o principe do sangue do vai-e-volta. 9a ed. Rio de Janeiro: José Olympio, 2012 